\title{
Complete genome sequence of Deinococcus maricopensis type strain (LB-34 ${ }^{\mathrm{T}}$ )
}

\author{
Rüdiger Pukall ${ }^{1}$, Ahmet Zeytun ${ }^{2,3}$, Susan Lucas ${ }^{2}$, Alla Lapidus ${ }^{2}$, Nancy Hammon ${ }^{2}$, Shweta \\ Deshpande $^{2}$, Matt Nolann ${ }^{2}$, Jan-Fang Cheng ${ }^{2}$, Sam Pitluck ${ }^{2}$, Konstantinos Liolios ${ }^{2}$, Ioanna \\ Pagani $^{2}$, Natalia Mikhailova ${ }^{2}$, Natalia Ivanova ${ }^{2}$, Konstantinos Mavromatis ${ }^{2}$, Amrita Pati ${ }^{2}$, \\ Roxane Tapia ${ }^{2,3}$, Cliff $\mathrm{Han}^{2,3}$, Lynne Goodwin ${ }^{2,3}$, Amy Chen ${ }^{4}$, Krishna Palaniappan ${ }^{4}$, Miriam \\ Land $^{2,5}$, Loren Hauser ${ }^{2,5}$, Yun-Juan Chang ${ }^{2,5}$, Cynthia D. Jeffries ${ }^{2,5}$, Evelyne-Marie Brambilla ${ }^{1}$, \\ Manfred Rohde ${ }^{6}$, Markus Göker ${ }^{1}$, J. Chris Detter ${ }^{2,3}$, Tanja Woyke ${ }^{2}$, James Bristow ${ }^{2}$, Jonathan \\ A. Eisen ${ }^{2,7}$, Victor Markowitz ${ }^{4}$, Philip Hugenholtz ${ }^{2,8}$, Nikos C. Kyrpides ${ }^{2}$, and Hans-Peter \\ Klenk $^{1 *}$ \\ ${ }^{1}$ DSMZ - German Collection of Microorganisms and Cell Cultures GmbH, Braunschweig, \\ Germany \\ ${ }^{2}$ DOE Joint Genome Institute, Walnut Creek, California, USA \\ ${ }^{3}$ Los Alamos National Laboratory, Bioscience Division, Los Alamos, New Mexico USA \\ ${ }^{4}$ Biological Data Management and Technology Center, Lawrence Berkeley National \\ Laboratory, Berkeley, California, USA \\ ${ }^{5}$ Lawrence Livermore National Laboratory, Livermore, California, USA \\ ${ }^{6} \mathrm{HZI}$ - Helmholtz Centre for Infection Research, Braunschweig, Germany \\ ${ }^{7}$ University of California Davis Genome Center, Davis, California, USA \\ ${ }^{8}$ Australian Centre for Ecogenomics, School of Chemistry and Molecular Biosciences, The \\ University of Queensland, Brisbane, Australia \\ *Corresponding author: Hans-Peter Klenk
}

Keywords: aerobic, non-motile, Gram-positive, radiation-resistant, mesophilic, chemoorganotrophic, Deinococcaceae, GEBA

Deinococcus maricopensis (Rainey and da Costa 2005) is a member of the genus Deinococ-
cus, which is comprised of 44 validly named species and is located within the deeply
branching bacterial phylum Deinococcus-Thermus. Strain LB- $34^{\top}$ was isolated from a soil
sample from the Sonoran Desert in Arizona. Various species of the genus Deinococcus are
characterized by extreme radiation resistance, with D. maricopensis being resistant in excess
of $10 \mathrm{kGy}$. Even though the genomes of three Deinococcus species, D. radiodurans, D. geo-
thermalis and D. deserti, have already been published, no special physiological characteristic
is currently known that is unique to this group. It is therefore of special interest to analyze the
genomes of additional species of the genus Deinococcus to better understand how these spe-
cies adapted to gamma- or UV ionizing-radiation. The 3,498,530 bp long genome of D. ma-
ricopensis with its 3,301 protein-coding and 66 RNA genes consists of one circular chromo-
some and is a part of the Genomic Encyclopedia of Bacteria and Archaea project.

\section{Introduction}

Strain LB-34 ${ }^{\mathrm{T}}$ (= DSM 21211 = NRRL B-23946 = LMG 22137) is the type strain of Deinococcus maricopensis [1]. In addition to the type strain LB$34^{\mathrm{T}}$, two more strains of this species, KR 1 and KR 23, were characterized by Rainey et al. [1]. The generic name derives from the Greek words 'deinos' meaning 'strange or unusual' and 'coccus' meaning 'a grain or berry' [2]. The species epithet is derived from the Neo-Latin word 'maricopensis' referring to the Maricopa Nation, a native tribe in Arizona [1]. Strain LB $34^{\mathrm{T}}$ was isolated from desert soil in Arizona and described by Rainey et al. in 2005 [1]. The genus Deinococcus was proposed in 1981 by Brooks and Murray [2] to separate the distinct radiation-resistant species from the genus Micrococcus in which those species 
were originally classified. With the description of Deinobacter grandis by Oyaizu et al. [3], a second genus was placed to the family Deinococcaceae, and in 1997 Rainey et al. proposed to transfer Deinobacter to the genus Deinococcus, based on investigations of the phylogenetic diversity of the Deinococci as determined by $16 \mathrm{~S}$ rRNA gene sequence analysis. In conclusion, an emended description of the genus Deinococcus was published, showing that the cells can be spherical or rodshaped [4]. Members of the genus Deinococcus were isolated from various environmental habitats including air [5-7], arid soil [1,8-12], water and activated sludge [13-15], alpine environments [16], rhizosphere [17], Antarctica [18], hot springs [19], aquifer [20], marine fish [21] and radioactive sites [22]. Here we present a summary classification and a set of features for D. maricopensis LB$34^{\mathrm{T}}$, together with the description of the complete genomic sequencing and annotation.

\section{Classification and features}

A representative genomic $16 \mathrm{~S}$ rRNA sequence of strain LB-34 ${ }^{\mathrm{T}}$ was compared using NCBI BLAST under default settings (e.g., considering only the high-scoring segment pairs (HSPs) from the best 250 hits) with the most recent release of the Greengenes database [23] and the relative frequencies, weighted by BLAST scores, of taxa and keywords (reduced to their stem [24]) were determined. The single most frequent genus was Deinococcus (100.0\%) (114 hits in total). Regarding the three hits to sequences from members of the species, the average identity within HSPs was 99.9\%, whereas the average coverage by HSPs was $97.6 \%$. Regarding the 77 hits to sequences from other members of the genus, the average identity within HSPs was $91.5 \%$, whereas the average coverage by HSPs was 60.5\%. Among all other species, the one yielding the highest score was $D$. radiodurans, which corresponded to an identity of $91.2 \%$ and an HSP coverage of $88.0 \%$. The highest-scoring environmental sequence was AY905380 ('Extensive ionizing-radiation-resistant recovered sonoran and description nine new species genus Deinococcus obtained single mixed agricultural/open desert soil clone L14-471'), which showed an identity of $98.1 \%$ and a HSP coverage of $70.2 \%$. The five most frequent keywords within the labels of environmental samples which yielded hits were 'skin' (7.7\%), 'litholog/stream' (2.8\%), 'fossa' (2.4\%), 'microbi' $(2.4 \%)$ and 'forearm' (2.1\%) (136 hits in total).
Environmental samples which yielded hits of a higher score than the highest scoring species were not found.

Figure 1 shows the phylogenetic neighborhood of D. maricopensis LB-34T in a $16 \mathrm{~S}$ rRNA based tree. The sequences of the four identical 16S rRNA gene copies in the genome differ by one nucleotide from the previously published $16 \mathrm{~S}$ rRNA sequence (AY743274).

The cells of $D$. maricopensis are rod-shaped, up to $6 \mu \mathrm{m}$ in length and $2.0 \mu \mathrm{m}$ wide (Figure 2). D. maricopensis is a Gram-positive, non-spore-forming bacterium (Table 1). Colonies on Rich medium are orange to pink. The cells are non-motile. The organism is chemoorganotrophic [1]. The temperature range for growth is $10^{\circ}$ to $45^{\circ} \mathrm{C}$, with an optimum at $40^{\circ} \mathrm{C}$ [1]. Cytochrome oxidase and catalase activity have been observed [1]. Strains may utilize L-arabinose, cellobiose, galactose, glucose, mannose, maltose, sucrose, trehalose, glucosamine, glycerol, malate, asparagine, aspartate, glutamate, L-glutamine, ornithine and proline. Fructose can be used by strain KR23, but not by strain LB-34T [1]. Strain LB-34 ${ }^{\mathrm{T}}$ showed similar levels of desiccation tolerance of up to four weeks as compared to D. radiodurans strain $\mathrm{R}^{\mathrm{T}}{ }^{\mathrm{T}}$. Strain LB-34 is resistant to $>10 \mathrm{kGy}$, but more sensitive to ionizing radiation than strain D. radiodurans $\mathrm{R} 1^{\mathrm{T}}$ [1].

\section{Chemotaxonomy}

The major cellular fatty acids of the strain LB-34T were identified as iso- $\mathrm{C}_{15: 0}$, iso- $\mathrm{C}_{17: 0}$ and $\mathrm{C}_{16: 0}$. Menaquinone 8 (MK-8) was determined as the major respiratory quinone of the strain. Phosphoglycolipid and glycolipid pattern are similar to those of other Deinococcus species [1]. No data are available for strain LB-34 ${ }^{\mathrm{T}}$ showing the peptidoglycan type of the cell wall.

\section{Genome sequencing and annotation Genome project history}

This organism was selected for sequencing on the basis of its phylogenetic position [45], and is part of the Genomic Encyclopedia of Bacteria and Archaea project [46]. The genome project is deposited in the Genomes On Line Database [29] and the complete genome sequence is deposited in GenBank. Sequencing, finishing and annotation were performed by the DOE Joint Genome Institute (JGI). A summary of the project information is shown in Table 2. 


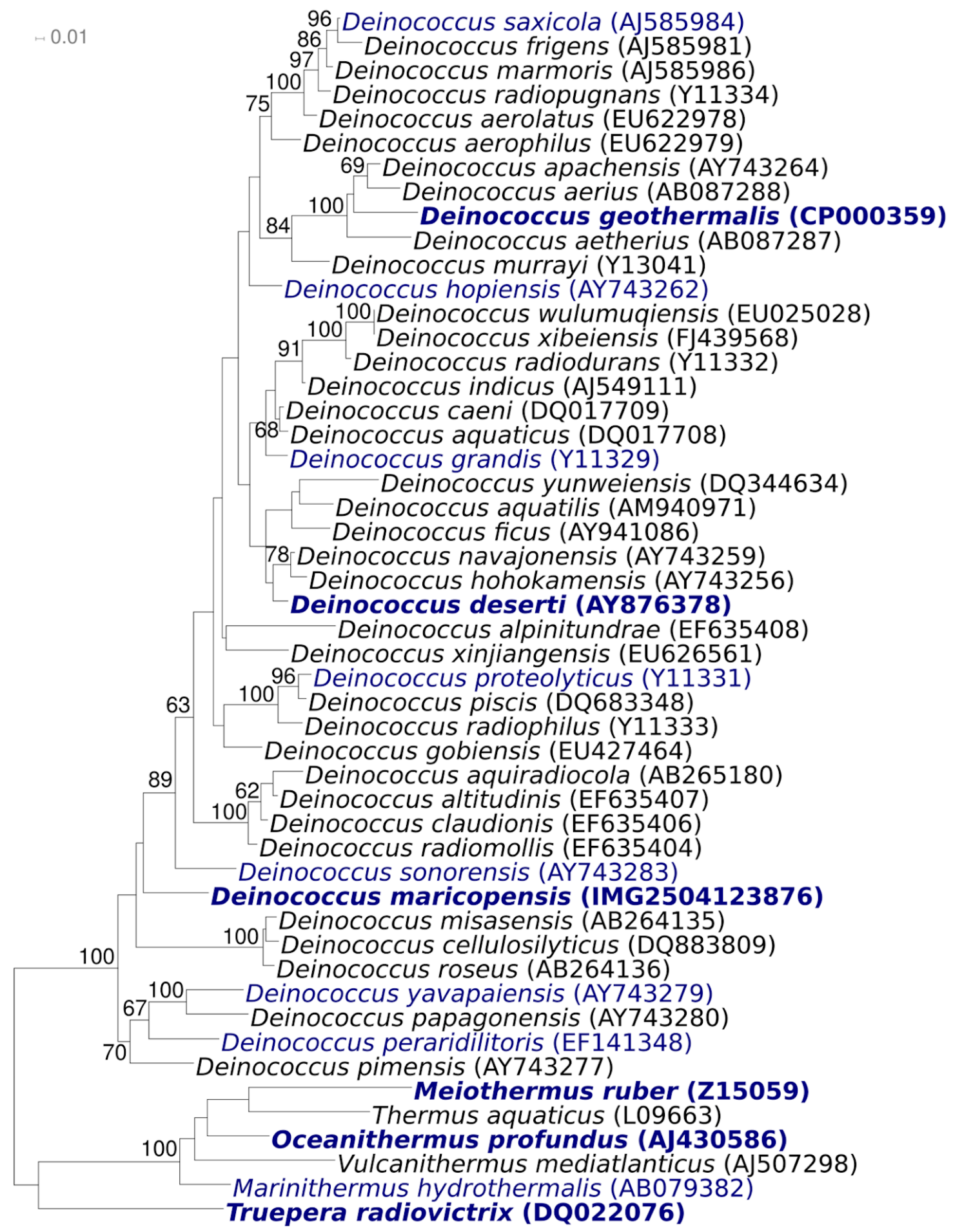

Figure 1. Phylogenetic tree highlighting the position of $D$. maricopensis relative to the other type strains within the family Deinococcaceae. The tree was inferred from 1,382 aligned characters $[25,26]$ of the $16 \mathrm{~S}$ rRNA gene sequence under the maximum likelihood criterion [27] and rooted in accordance with the current taxonomy. The branches are scaled in terms of the expected number of substitutions per site. Numbers above branches are support values from 1,000 bootstrap replicates [28] if larger than $60 \%$. Lineages with type strain genome sequencing projects registered in GOLD [29] are shown in blue, and published genomes in bold [30-34]. The genome of D. radiodurans published by White at al. in 1999 [35] later turned out not to be from the type strain [36]. 


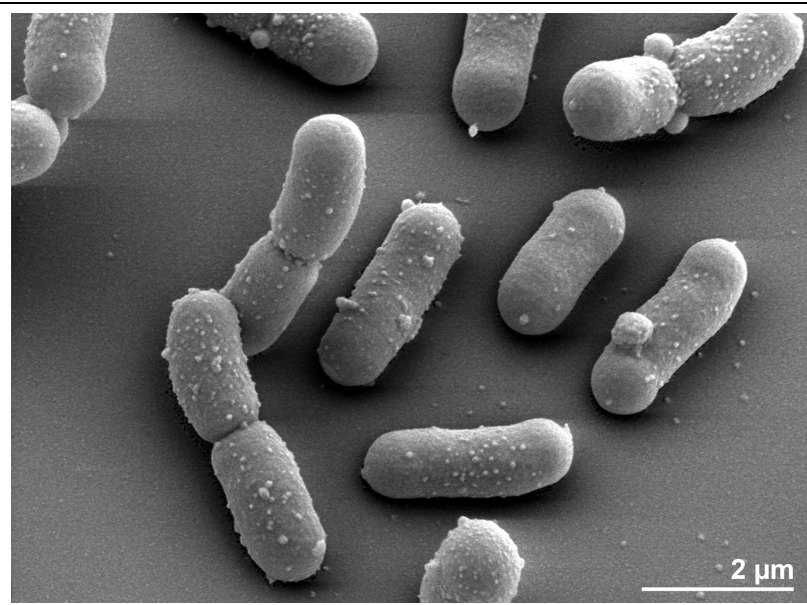

Figure 2. Scanning electron micrograph of D. maricopensis LB-34 ${ }^{\top}$

Table 1. Classification and general features of D. maricopensis LB-34 ${ }^{\top}$ according to the MIGS recommendations [37].

\begin{tabular}{|c|c|c|c|}
\hline MIGS ID & Property & Term & Evidence code \\
\hline & \multirow{8}{*}{ Current classification } & Domain Bacteria & TAS [38] \\
\hline & & Phylum Deinococcus-Thermus & TAS [39] \\
\hline & & Class Deinococci & TAS $[40,41]$ \\
\hline & & Order Deinococcales & TAS [4] \\
\hline & & Family Deinococcaceae & TAS $[2,4]$ \\
\hline & & Genus Deinococcus & TAS $[2,4]$ \\
\hline & & Species Deinococcus maricopensis & TAS $[1,42]$ \\
\hline & & Type strain LB-34 & TAS [1] \\
\hline & Gram stain & positive & TAS [1] \\
\hline & Cell shape & rods & TAS [1] \\
\hline & Motility & non-motile & TAS [1] \\
\hline & Sporulation & none & TAS [1] \\
\hline & Temperature range & mesophile, $10^{\circ} \mathrm{C}-45^{\circ} \mathrm{C}$ & TAS [1] \\
\hline & Optimum temperature & $40^{\circ} \mathrm{C}$ & TAS [1] \\
\hline & Salinity & not reported & \\
\hline \multirow[t]{3}{*}{ MIGS-22 } & Oxygen requirement & aerobic & TAS [1] \\
\hline & Carbon source & carbohydrates & TAS [1] \\
\hline & Energy metabolism & chemoorganotroph & TAS $[1,2]$ \\
\hline MIGS-6 & Habitat & soil & TAS [1] \\
\hline MIGS-15 & Biotic relationship & free-living & NAS \\
\hline \multirow[t]{3}{*}{ MIGS-14 } & Pathogenicity & none & NAS \\
\hline & Biosafety level & 1 & TAS [43] \\
\hline & Isolation & soil & TAS [1] \\
\hline MIGS-4 & Geographic location & Sonoran Desert, Arizona, USA & TAS [1] \\
\hline MIGS-5 & Sample collection time & 1999 & NAS \\
\hline MIGS-4.1 & Latitude & 32.93 & NAS \\
\hline MIGS-4.2 & Longitude & -112.30 & NAS \\
\hline MIGS-4.3 & Depth & not reported & \\
\hline MIGS-4.4 & Altitude & not reported & \\
\hline
\end{tabular}

Evidence codes - IDA: Inferred from Direct Assay (first time in publication); TAS: Traceable Author Statement (i.e., a direct report exists in the literature); NAS: Non-traceable Author Statement (i.e., not directly observed for the living, isolated sample, but based on a generally accepted property for the species, or anecdotal evidence). These evidence codes are from of the Gene Ontology project [44]. If the evidence code is IDA, then the property was directly observed by one of the authors or an expert mentioned in the acknowledgements. 
Table 2. Genome sequencing project information

\begin{tabular}{lll}
\hline MIGS ID & Property & Term \\
\hline MIGS-31 & Finishing quality & Finished \\
MIGS-28 & Libraries used & Three genomic libraries: one 454 pyrosequence standard library, \\
MIGS-29 & Sequencing platforms & one 454 PE library (7 kb insert size), one Illumina library \\
MIGS-31.2 & Sequencing coverage & $170.9 \times$ Illumina; 75.4 × pyrosequence \\
MIGS-30 & Assemblers & Newbler version 2.3-PreRelease-10-21-2009-gcc-4.1.2-threads, \\
MIGS-32 & Gene calling method & Velvet version 0.7.63, phrap \\
& INSDC ID & CP002igal 1.4, GenePRIMP \\
& Genbank Date of Release & January 20, 2011 \\
& GOLD ID & Gc01597 \\
& NCBI project ID & 43461 \\
& Database: IMG-GEBA & 2503982045 \\
MIGS-13 & Source material identifier & DSM 21211 \\
& Project relevance & Tree of Life, GEBA \\
\hline
\end{tabular}

\section{Growth conditions and DNA isolation}

D. maricopensis LB-34 ${ }^{\mathrm{T}}$, DSM 21211, was grown in DSMZ medium 736 (Rich Medium) [47] at $28^{\circ} \mathrm{C}$. DNA was isolated from $0.5-1 \mathrm{~g}$ of cell paste using MasterPure Gram-positive DNA purification kit (Epicentre MGP04100) following the standard protocol as recommended by the manufacturer, with a modification in cell lysis by adding $20 \mu \mathrm{l}$ lysozyme $(100 \mathrm{mg} / \mu \mathrm{l})$, and $10 \mu \mathrm{l}$ mutanolysine, achromopeptidase and lysostphine, each, for 40 min at $37^{\circ} \mathrm{C}$, followed by one hour incubation on ice after the MPC step. DNA is available through the DNA Bank Network [48,49].

\section{Genome sequencing and assembly}

The genome was sequenced using a combination of Illumina and 454 sequencing platforms. All general aspects of library construction and sequencing can be found at the JGI website [50]. Pyrosequencing reads were assembled using the Newbler assembler version 2.3 (Roche). The initial Newbler assembly consisting of 58 contigs in two scaffolds was converted into a phrap assembly by [51] making fake reads from the consensus, to collect the read pairs in the 454 paired end library. Illumina GAii sequencing data (957.8 Mb) were assembled with Velvet version 0.7.63 [52] and the consensus sequences were shredded into $1.5 \mathrm{~kb}$ overlapped fake reads and assembled together with the 454 data. The 454 draft assembly was based on $234.5 \mathrm{Mb}$ 454 draft data and all of the 454 paired end data. Newbler parameters are -consed -a 50 -l 350 -g -m $\mathrm{ml}$ 20. The Phred/Phrap/Consed software package [51] was used for sequence assembly and quality assessment in the subsequent finishing process. After the shotgun stage, reads were assembled with parallel phrap (High Performance Software, LLC). Possible mis-assemblies were corrected with gapResolution [50], Dupfinisher [53], or sequencing cloned bridging PCR fragments with subcloning or transposon bombing (Epicentre Biotechnologies, Madison, WI). Gaps between contigs were closed by editing in Consed, by PCR and by Bubble PCR primer walks (J.-F.Chang, unpublished). A total of 255 additional reactions were necessary to close gaps and to raise the quality of the finished sequence. Illumina reads were also used to correct potential base errors and increase consensus quality using a software Polisher developed at JGI [54]. The error rate of the completed genome sequence is less than 1 in 100,000. Together, the combination of the Illumina and 454 sequencing platforms provided $246.3 \times$ coverage of the genome. The final assembly contained 872,337 pyrosequence and $16,604,657$ Illumina reads.

\section{Genome annotation}

Genes were identified using Prodigal [55] as part of the Oak Ridge National Laboratory genome annotation pipeline, followed by a round of manual curation using the JGI GenePRIMP pipeline [56]. The predicted CDSs were translated and used to search the National Center for Biotechnology Information (NCBI) nonredundant database, UniProt, TIGR-Fam, Pfam, PRIAM, KEGG, COG, and InterPro databases. Additional gene prediction analysis and functional annotation was performed 
within the Integrated Microbial Genomes - Expert Review (IMG-ER) platform [57].

\section{Genome properties}

The genome consists of a 3,498,530 bp long chromosome with a $\mathrm{G}+\mathrm{C}$ content of $69.8 \%$ (Figure 3 and Table 3). Of the 3,367 genes predicted, 3,301 were protein-coding genes, and 66 RNAs; 37 pseudogenes were also identified. The majority of the protein-coding genes $(70.3 \%)$ were assigned with a putative function while the remaining ones were annotated as hypothetical proteins. The distribution of genes into COGs functional categories is presented in Table 4.

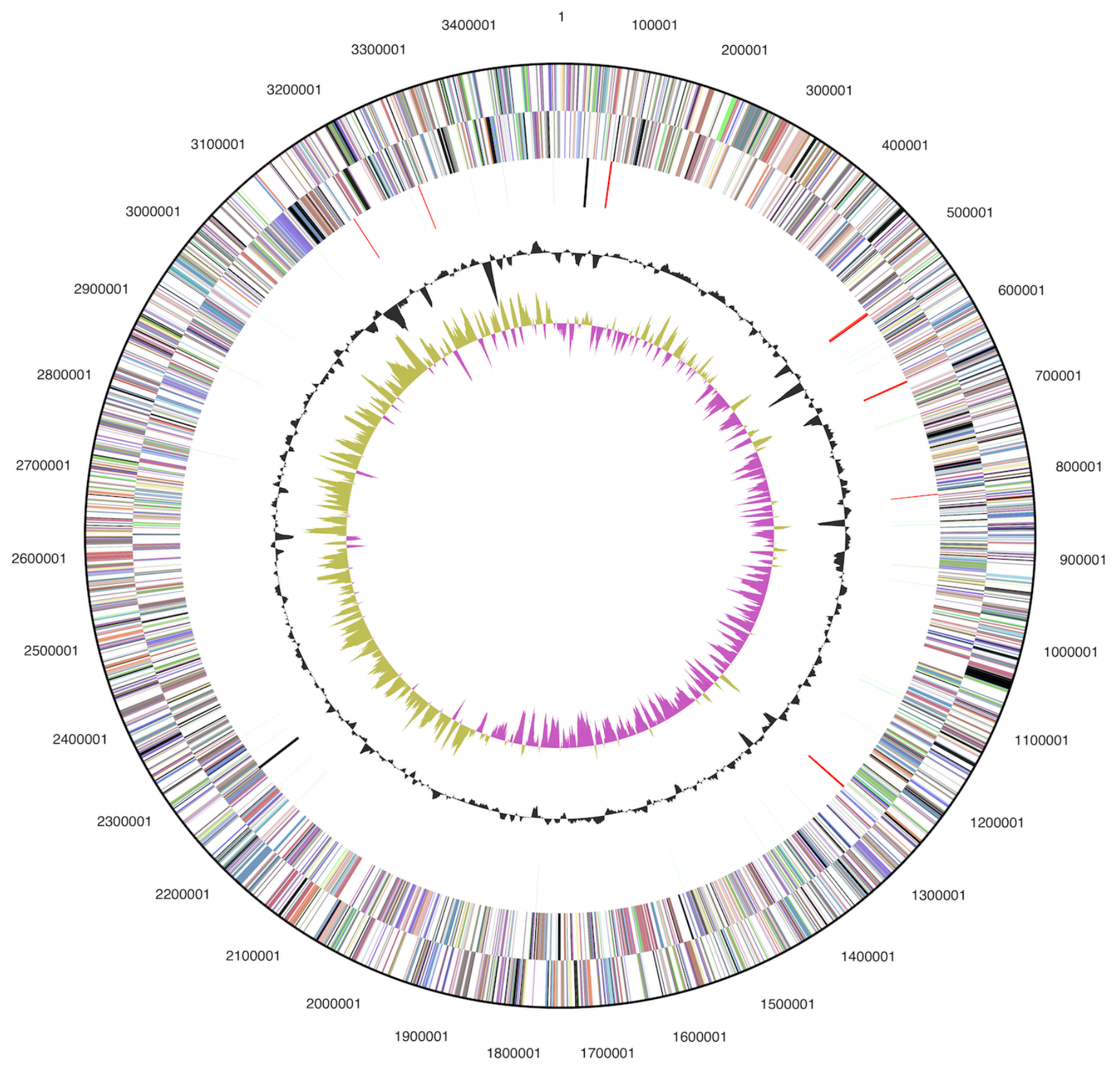

Figure 3. Graphical circular map of the chromosome. From outside to the center: Genes on forward strand (color by COG categories), Genes on reverse strand (color by COG categories), RNA genes (tRNAs green, rRNAs red, other RNAs black), GC content, GC skew. 
Table 3. Genome Statistics

\begin{tabular}{lrr}
\hline Attribute & Value & \% of Total \\
\hline Genome size (bp) & $3,498,530$ & $100.00 \%$ \\
DNA coding region (bp) & $3,127,041$ & $89.38 \%$ \\
DNA G+C content (bp) & $2,442,849$ & $69.83 \%$ \\
Number of replicons & 1 & \\
Extrachromosomal elements & 0 & \\
Total genes & 3,367 & $100.00 \%$ \\
RNA genes & 66 & $1.96 \%$ \\
rRNA operons & 4 & \\
Protein-coding genes & 3,301 & $98.04 \%$ \\
Pseudo genes & 37 & $1.10 \%$ \\
Genes with function prediction & 2,366 & $70.27 \%$ \\
Genes in paralog clusters & 368 & $10.93 \%$ \\
Genes assigned to COGs & 2,412 & $71.64 \%$ \\
Genes assigned Pfam domains & 2,495 & $74.10 \%$ \\
Genes with signal peptides & 1,005 & $29.85 \%$ \\
Genes with transmembrane helices & 662 & $19.66 \%$ \\
CRISPR repeats & 0 & \\
\hline
\end{tabular}

Table 4. Number of genes associated with the general COG functional categories

\begin{tabular}{lrrl}
\hline Code & value & \%age & Description \\
\hline J & 160 & 6.0 & Translation, ribosomal structure and biogenesis \\
A & 0 & 0.0 & RNA processing and modification \\
K & 188 & 7.1 & Transcription \\
L & 109 & 4.1 & Replication, recombination and repair \\
B & 2 & 0.1 & Chromatin structure and dynamics \\
D & 29 & 1.1 & Cell cycle control, cell division, chromosome partitioning \\
Y & 0 & 0.0 & Nuclear structure \\
V & 45 & 1.7 & Defense mechanisms \\
T & 195 & 7.3 & Signal transduction mechanisms \\
M & 137 & 5.2 & Cell wall/membrane/envelope biogenesis \\
N & 15 & 0.6 & Cell motility \\
Z & 1 & 0.0 & Cytoskeleton \\
W & 0 & 0.0 & Extracellular structures \\
U & 43 & 1.6 & Intracellular trafficking, secretion, and vesicular transport \\
O & 113 & 4.3 & Posttranslational modification, protein turnover, chaperones \\
C & 125 & 4.7 & Energy production and conversion \\
G & 205 & 7.7 & Carbohydrate transport and metabolism \\
E & 237 & 8.9 & Amino acid transport and metabolism \\
F & 77 & 2.9 & Nucleotide transport and metabolism \\
H & 119 & 4.5 & Coenzyme transport and metabolism \\
I & 105 & 4.0 & Lipid transport and metabolism \\
P & 121 & 4.6 & Inorganic ion transport and metabolism \\
Q & 60 & 2.3 & Secondary metabolites biosynthesis, transport and catabolism \\
R & 334 & 12.6 & General function prediction only \\
S & 238 & 9.0 & Function unknown \\
- & 955 & 28.4 & Not in COGs \\
\hline & & &
\end{tabular}




\section{Acknowledgements}

We would like to gratefully acknowledge the help of Gabriele Gehrich-Schröter (DSMZ) for growing D. maricopensis cultures. This work was performed under the auspices of the US Department of Energy Office of Science, Biological and Environmental Research Program, and by the University of California, Lawrence Berkeley National Laboratory under contract No. DE-

\section{References}

1. Rainey FA, Ray K, Ferreira M, Gatz BZ, Nobre MF, Bagaley D, Rash BA, Park NJ, Earl AM, Shank NC, et al. Extensive diversity of ionizing-radiationresistant bacteria recovered from Sonoran Desert soil and description of nine new species of the genus Deinococcus obtained from a single soil sample. Appl Environ Microbiol 2005; 71:5225-5235. PubMed doi:10.1128/AEM.71.9.5225-5235.2005

2. Brooks BW, Murray RGE. Nomenclature for "Micrococcus radiodurans" and other radiation-resistant cocci: Deinococcaceae fam. nov. and Deinococcus gen. nov., including five species. Int J Syst Bacteriol 1981; 31:353-360. doi:10.1099/00207713-31-3$\underline{353}$

3. Oyaizu H, Stackebrandt E, Schleifer KH, Ludwig W, Pohla H, Ito H, Hirata A, Oyaizu Y, Komagata K. A radiation-resistant rod-shaped bacterium, Deinobacter grandis gen. nov., sp. nov., with peptidoglycan containing ornithine. Int J Syst Bacteriol 1987; 37:62-67. doi:10.1099/00207713-37-1-62

4. Rainey FA, Nobre MF, Schumann P, Stackebrandt E, da Costa MS. Phylogenetic diversity of the Deinococci as determined by $16 \mathrm{~S}$ ribosomal DNA sequence comparison. Int / Syst Bacteriol 1997; 47:510-514. PubMed doi:10.1099/00207713-47-2$\underline{510}$

5. Weon HY, Kim BY, Schumann P, Son JA, Jang J, Go SJ, Kwon SW. Deinococcus cellulosilyticus sp. nov., isolated from air. Int J Syst Evol Microbiol 2007; 57:1685-1688. PubMed doi:10.1099/ijs.0.64951-0

6. Yang $\mathrm{Y}$, Itoh $\mathrm{T}$, Yokobori $\mathrm{S}$, Itahashi $\mathrm{S}$, Shimada $\mathrm{H}$, Satoh K, Ohba H, Narumi I, Yamagishi A. Deinococcus aerius sp. nov., isolated from the high atmosphere. Int J Syst Evol Microbiol 2009; 59:18621866. PubMed doi:10.1099/ijs.0.007963-0

7. Yoo SH, Weon HY, Kim SJ, Kim YS, Kim BY, Kwon SW. Deinococcus aerolatus sp. nov. and Deinococcus aerophilus sp. nov., isolated from air samples. Int J Syst Evol Microbiol 2010; 60:1191-1195. PubMed doi:10.1099/ijs.0.016030-0

8. Rainey FA, Ferreira M, Nobre MF, Ray K, Bagaley D, Earl AM, Battista JR, Gómez-Silva B, McKay CP, da Costa MS. Deinococcus peraridilitoris sp. nov.,
AC02-05CH11231, Lawrence Livermore National Laboratory under Contract No. DE-AC52-07NA27344, and Los Alamos National Laboratory under contract No. DEAC02-06NA25396, UT-Battelle and Oak Ridge National Laboratory under contract DE-AC05-000R22725, as well as German Research Foundation (DFG) INST 599/1-2.

isolated from a coastal desert. Int / Syst Evol Microbiol 2007; 57:1408-1412. PubMed doi:10.1099/ijs.0.64956-0

9. de Groot A, Chapon V, Servant P, Christen R, Saux MF, Sommer S, Heulin T. Deinococcus deserti sp. nov., a gamma-radiation-tolerant bacterium isolated from the Sahara Desert. Int I Syst Evol Microbiol 2005; 55:2441-2446. PubMed doi:10.1099/ijs.0.63717-0

10. Peng F, Zhang L, Luo X, Dai J, An H, Tang Y, Fang C. Deinococcus xinjiangensis sp. nov., isolated from desert soil. Int J Syst Evol Microbiol 2009; 59:709713. PubMed doi:10.1099/ijs.0.004564-0

11. Yuan $M$, Zhang $W$, Dai $S$, Wu J, Wang $Y$, Tao T, Chen M, Lin M. Deinococcus gobiensis sp. nov., an extremely radiation-resistant bacterium. Int I Syst Evol Microbiol 2009; 59:1513-1517. PubMed doi:10.1099/ijs.0.004523-0

12. Wang W, Mao J, Zhang Z, Tang Q, Xie Y, Zhu J, Zhang L, Liu Z, Shi Y, Goodfellow M. Deinococcus wulumuqiensis sp. nov., and Deinococcus xibeiensis sp. nov., isolated from radiation-polluted soil. Int J Syst Evol Microbiol 2010; 60:2006-2010. PubMed doi:10.1099/ijs.0.015917-0

13. Im WT, Jung HM, Ten LN, Kim MK, Bora N, Goodfellow M, Lim S, Jung J, Lee ST. Deinococcus aquaticus sp. nov., isolated from fresh water, and Deinococcus caeni sp. nov., isolated from activated sludge. Int J Syst Evol Microbiol 2008; 58:23482353. PubMed doi:10.1099/ijs.0.64082-0

14. Kämpfer P, Lodders N, Huber B, Falsen E, Busse HJ. Deinococcus aquatilis sp. nov., isolated from water. Int J Syst Evol Microbiol 2008; 58:2803-2806. PubMed doi:10.1099/ijs.0.2008/001206-0

15. Asker D, Awad TS, Beppu T, Ueda K. Deinococcus aquiradiocola sp. nov., isolated from a radioactive site in Japan. Int / Syst Evol Microbiol 2009; 59:144149. PubMed doi:10.1099/ijs.0.65762-0

16. Callegan RP, Nobre MF, McTernan PM, Battista JR, Navarro-González R, McKay CP, da Costa MS, Rainey FA. Description of four novel psychrophilic, ionizing radiation-sensitive Deinococcus species from 
Pukall et al.

alpine environments. Int / Syst Evol Microbiol 2008; 58:1252-1258. PubMed doi:10.1099/ijs.0.65405-0

17. Lai WA, Kämpfer $P$, Arun AB, Shen FT, Huber B, Rekha PD, Young CC. Deinococcus ficus sp. nov., isolated from the rhizosphere of Ficus religiosa L. Int J Syst Evol Microbiol 2006; 56:787-791. PubMed doi:10.1099/ijs.0.64007-0

18. Hirsch P, Gallikowski CA, Siebert J, Peissl K, Kroppenstedt R, Schumann P, Stackebrandt E, Anderson R. Deinococcus frigens sp. nov., Deinococcus saxicola sp. nov., and Deinococcus marmoris sp. nov., low temperature and draught-tolerating, UVresistant bacteria from continental Antarctica. Syst App/ Microbiol 2004; 27:636-645. PubMed doi:10.1078/0723202042370008

19. Ferreira AC, Nobre MF, Rainey FA, Silva MT, Wait R, Burghardt J, Chung AP, da Costa MS. Deinococcus geothermalis sp. nov. and Deinococcus murrayi sp. nov., two extremely radiation-resistant and slightly thermophilic species from hot springs. Int J Syst Bacteriol 1997; 47:939-947. PubMed doi:10.1099/00207713-47-4-939

20. Suresh K, Reddy GS, Sengupta S, Shivaji S. Deinococcus indicus sp. nov., an arsenic-resistant bacterium from an aquifer in West Bengal, India. Int J Syst Evol Microbiol 2004; 54:457-461. PubMed doi:10.1099/ijs.0.02758-0

21. Shashidhar R, Bandekar JR. Deinococcus piscis sp. nov., a radiation-resistant bacterium isolated from a marine fish. Int J Syst Evol Microbiol 2009; 59:27142717. PubMed doi:10.1099/ijs.0.003046-0

22. Asker D, Awad TS, Beppu T, Ueda K. Deinococcus misasensis and Deinococcus roseus, novel members of the genus Deinococcus, isolated from a radioactive site in Japan. Syst Appl Microbiol 2008; 31:4349. PubMed doi:10.1016/j.syapm.2007.10.002

23. DeSantis TZ, Hugenholtz $P$, Larsen N, Rojas M, Brodie EL, Keller K, Huber T, Dalevi D, Hu P, Andersen GL. Greengenes, a chimera-checked 16S rRNA gene database and workbench compatible with ARB. Appl Environ Microbiol 2006; 72:50695072. PubMed doi:10.1128/AEM.03006-05

24. Porter MF. An algorithm for suffix stripping. Program: electronic library and information systems 1980; 14:130-137.

25. Castresana J. Selection of conserved blocks from multiple alignments for their use in phylogenetic analysis. Mol Biol Evol 2000; 17:540-552. PubMed

26. Lee C, Grasso C, Sharlow MF. Multiple sequence alignment using partial order graphs. Bioinformatics
2002; 18:452-464. PubMed

doi:10.1093/bioinformatics/18.3.452

27. Stamatakis A, Hoover $\mathrm{P}$, Rougemont J. A rapid bootstrap algorithm for the RAxML Web servers. Syst Biol 2008; 57:758-771. PubMed doi:10.1080/10635150802429642

28. Pattengale ND, Alipour M, Bininda-Emonds ORP, Moret BME, Stamatakis A. How many bootstrap replicates are necessary? Lect Notes Comput Sci 2009; 5541:184-200. doi:10.1007/978-3-642-02008-7_13

29. Liolios K, Chen IM, Mavromatis K, Tavernarakis N, Hugenholtz P, Markowitz VM, Kyrpides NC. The Genomes On Line Database (GOLD) in 2009: status of genomic and metagenomic projects and their associated metadata. Nucleic Acids Res 2009; 38:D346-D354. PubMed doi:10.1093/nar/gkp848

30. de Groot A, Dulermo R, Ortet P, Blanchard L, Guerin $\mathrm{P}$, Fernandez B, Vacherie B, Dossat C, Jolivet $\mathrm{E}$, Siguier $\mathrm{P}$, et al. Alliance of proteomics and genomics to unravel the specificities of Sahara bacterium Deinococcus deserti. PLoS Genet 2009; 5:e1000434. PubMed doi:10.1371/journal.pgen.1000434

31. Makarova KS, Omelchenko MV, Gaidamakova EK, Matrosova VY, Vasilenko A, Zhai M, Lapidus A, Copeland A, Kim E, Land M, et al. Deinococcus geothermalis: the pool of extreme radiation resistance genes shrinks. PLoS ONE 2007; 2:e955. PubMed doi:10.1371/journal.pone.0000955

32. Ivanova N, Rhode C, Munk C, Nolan M, Lucas S, Glavina Del Rio T, Tice H, Deshpande S, Cheng JF, Tapia R, et al. Complete genome sequence of Truepera radiovictrix type strain $\left(\mathrm{RQ}-24^{\mathrm{T}}\right)$. Stand $\mathrm{Ge}-$ nomic Sci 2011; 4:91-99. PubMed doi:10.4056/sigs.1563919

33. Tindall BJ, Sikorski J, Lucas S, Goltsman E, Copeland A, Glavina Del Rio T, Nolan M, Tice H, Cheng JF, Han $\mathrm{C}$, et al. Complete genome sequence of Meiothermus ruber type strain $\left(21^{\top}\right)$. Stand Genomic Sci 2010; 3:26-36. PubMed doi:10.4056/sigs.1032748

34. Pati A, Zhang X, Lapidus A, Nolan M, Lucas S, Glavina Del Rio T, Tice H, Cheng JF, Tapia R, Han C, et al. Complete genome sequence of Oceanithermus profundus type strain $\left(506^{\top}\right)$. Stand Genomic Sci 2011; 4:210-220. doi:10.4056/sigs.1513795

35. White O, Eisen JA, Heidelberg JF, Hickey EK, Peterson JD, Dodson RJ, Haft DH, Gwinn ML, Nelson WC, Richardson DL, et al. Genome sequence of the radioresistant bacterium Deinococcus radiodurans R1. Science 1999; 286:1571-1577. PubMed doi:10.1126/science.286.5444.1571 
36. Corrections and Clarifications. [Erratum: Genome sequence of the radioresistant bacterium Deinococcus radiodurans R1.]. Science 2004; 303:766b. doi:10.1126/science.303.5659.766b

37. Field D, Garrity G, Gray T, Morrison N, Selengut J, Sterk P, Tatusova T, Thomson N, Allen MJ, Angiuoli $\mathrm{SV}$, et al. The minimum information about a genome sequence (MIGS) specification. Nat Biotechnol 2008; 26:541-547. PubMed

doi:10.1038/nbt1360

38. Woese CR, Kandler O, Wheelis ML. Towards a natural system of organisms: proposal for the domains Archaea, Bacteria, and Eucarya. Proc Natl Acad Sci USA 1990; 87:4576-4579. PubMed doi:10.1073/pnas.87.12.4576

39. Weisburg WG, Giovannoni SJ, Woese CR. The Deinococcus-Thermus phylum and the effect of rRNA composition on phylogenetic tree construction. Syst App/ Microbiol 1989; 11:128-134. PubMed

40. List Editor. Validation List no. 85. Validation of publication of new names and new combinations previously effectively published outside the IJSEM. Int J Syst Evol Microbiol 2002; 52:685-690. PubMed doi:10.1099/ijs.0.02358-0

41. Garrity GM, Holt JG. Class I. Deinococci class. nov. In: Garrity GM, Boone DR, Castenholz RW (eds), Bergey's Manual of Systematic Bacteriology, Second Edition, Volume 1, Springer, New York, 2001, p. 395.

42. List Editor. Validation of publication of new names and new combinations previously effectively published outside the IJSEM. List no. 106. Int I Syst Evol Microbiol 2005; 55:2235-2238.

doi:10.1099/ijs.0.64108-0

43. Classification of bacteria and archaea in risk groups. TRBA 466, http://www.baua.de

44. Ashburner M, Ball CA, Blake JA, Botstein D, Butler $\mathrm{H}$, Cherry JM, Davis AP, Dolinski K, Dwight SS, Eppig JT, et al. Gene Ontology: tool for the unification of biology. Nat Genet 2000; 25:25-29. PubMed doi:10.1038/75556

45. Klenk HP, Göker M. En route to a genome-based classification of Archaea and Bacteria? Syst Appl Microbiol 2010; 33:175-182. PubMed doi:10.1016/j.syapm.2010.03.003

46. Wu D, Hugenholtz P, Mavromatis K, Pukall R, Dalin E, Ivanova NN, Kunin V, Goodwin L, Wu M,
Tindall BJ, et al. A phylogeny-driven genomic encyclopaedia of Bacteria and Archaea. Nature 2009; 462:1056-1060. PubMed doi:10.1038/nature08656

47. List of growth media used at DSMZ: http://www.dsmz.de/microorganisms/media list.php

48. Gemeinholzer B, Dröge $\mathrm{G}$, Zetzsche $\mathrm{H}$, Haszprunar G, Klenk HP, Güntsch A, Berendsohn WG, Wägele JW. The DNA Bank Network: the start from a German initiative. Biopreservation and Biobanking (In press).

49. DNA Bank Network. http://www.dnabanknetwork.org

50. DOE Joint Genome Institute. http://www.jgi.doe.gov

51. Phrap and Phred for Windows. MacOS, Linux, and Unix. http://www.phrap.com

52. Zerbino DR, Birney E. Velvet: algorithms for de novo short read assembly using de Bruijn graphs. Genome Res 2008; 18:821-829. PubMed doi:10.1101/gr.074492.107

53. Han C, Chain P. 2006. Finishing repeat regions automatically with Dupfinisher. in Proceeding of the 2006 international conference on bioinformatics \& computational biology. Edited by Hamid R. Arabnia \& Homayoun Valafar, CSREA Press. June 26-29, 2006: 141-146.

54. Lapidus A, LaButti K, Foster B, Lowry S, Trong S, Goltsman E. POLISHER: An effective tool for using ultra short reads in microbial genome assembly and finishing. AGBT, Marco Island, FL, 2008.

55. Hyatt $\mathrm{D}$, Chen $\mathrm{GL}$, LoCascio PF, Land ML, Larimer FW, Hauser LJ. Prodigal: prokaryotic gene recognition and translation initiation site identification. BMC Bioinformatics 2010; 11:119. PubMed doi:10.1186/1471-2105-11-119

56. Pati A, Ivanova NN, Mikhailova N, Ovchinnikova G, Hooper SD, Lykidis A, Kyrpides NC. GenePRIMP: a gene prediction improvement pipeline for prokaryotic genomes. Nat Methods 2010; 7:455457. PubMed doi:10.1038/nmeth.1457

57. Markowitz VM, Ivanova NN, Chen IMA, Chu K, Kyrpides NC. IMG ER: a system for microbial genome annotation expert review and curation. Bioinformatics 2009; 25:2271-2278. PubMed doi:10.1093/bioinformatics/btp393 